\title{
POR UNA DEMOCRACIA DE INSTITUCIONES PARA AMÉRICA LATINA ${ }^{1}$
}

\author{
Ignacio Walker
}

En el período comprendido entre 2005 y 2008, quince elecciones presidenciales han tenido lugar en la región. Sin embargo, en los últimos veinticinco años, trece gobiernos elegidos democráticamente no han podido concluir su período constitucional. Por un lado, se consolida la democracia electoral, con elecciones libres, competitivas y transparentes, y niveles no despreciables de participación electoral. Por otro lado, sin embargo, existe un fuerte "déficit democrático" en la región, referido principalmente a la brecha que se advierte entre aspiraciones y realidades. Cómo transitar desde la democracia electoral hacia una auténtica democracia representativa, entendida esta última como “democracia de instituciones”, en la perspectiva más amplia de la gobernabilidad democrática aparece, hoy por hoy, y en una perspectiva de futuro, como el principal desafío político de América Latina. Ése es el tema que se aborda en el presente trabajo.

Palabras clave: Democracia; América Latina; instituciones; democracia representativa; populismo.

Recibido: octubre de 2008. Aceptado: diciembre de 2008.

Ignacio Walker. Doctor en Ciencia Política de la Universidad de Princeton (Estados Unidos). Investigador de CIEPLAN, Santiago, Chile.

${ }^{1}$ Este trabajo es parte del proyecto "Nueva Agenda Económica y Social en América Latina”, llevado a cabo por CIEPLAN y el Instituto Fernando H. Cardoso, financiado por el BID, PNUD y AECI.

Estudios Públicos, 113 (verano 2009). 


\section{Introducción ${ }^{2}$}

Cómo transitar desde la democracia electoral hacia una auténtica democracia representativa, entendida esta última como "democracia de instituciones”, en la perspectiva más amplia de la gobernabilidad democrática aparece, hoy por hoy, y en una perspectiva de futuro, como el principal desafío político de América Latina ${ }^{3}$.

En el período comprendido entre 2005 y 2008, quince elecciones presidenciales han tenido lugar en la región ${ }^{4}$. La democracia electoral, basada en la generación de cargos de representación popular mediante elecciones libres, competitivas y transparentes, tiende a imponerse en la región como nunca antes en nuestra historia. Recordemos que, hacia fines de la década de 1970, sólo Colombia, Venezuela y Costa Rica celebraban elecciones libres y democráticas, por lo que se trata de un gran logro que no debe subestimarse. Sin embargo, también es cierto que, tras los procesos de transición a la democracia iniciados hacia fines de la década de 1970 y comienzos de la década de 1980, trece gobiernos elegidos democráticamente no han podido concluir su período constitucional ${ }^{5}$. El contraste entre ambas situaciones nos dice bastante acerca de las tensiones y contradicciones que enfrentan las nuevas democracias de América Latina. El titular de un reportaje en un semanario de la región reflejó esta problemática de manera elocuente, algu-

\footnotetext{
${ }^{2}$ Se agradecen los comentarios formulados a un borrador inicial de este trabajo por parte de Edgardo Boeninger, Maria Herminia Tavares, Scott Mainwaring, Fernando Luiz Abrucio, Marcus André Melo y Cristóbal Aninat. Como siempre, cabe señalar que ellos no tienen responsabilidad por el contenido del mismo.

${ }^{3}$ Dada la gran diversidad y heterogeneidad de la región, cabe señalar que las reflexiones que siguen contienen, necesariamente, un nivel de generalizaciones que muchas veces no dan cuenta de las distinciones y especificaciones que habría que hacer a partir de dichas características de diversidad y heterogeneidad. Hemos excluido del análisis a los países del Caribe, por lo que generalmente tenemos en cuenta la realidad de México, América Central y América del Sur (principalmente esta última).

${ }^{4}$ Honduras, Chile, Bolivia, Costa Rica, Perú, Colombia, México, Brasil, Ecuador, Nicaragua, Venezuela, Guatemala, Argentina, Paraguay y República Dominicana —hemos incluido a este último país a pesar de que, en estricto rigor, es parte del Caribe.

${ }^{5}$ Hernán Siles Suazo (1985), Gonzalo Sánchez de Lozada (2003) y Carlos Mesa (2005), en Bolivia; Abdalá Bucarán (1997), Jamil Mahuad (1999) y Lucio Gutiérrez (2005), en Ecuador; Fernando Collor de Mello, en Brasil (1992); Jorge Serrano Elías, en Guatemala (1993); Carlos Andrés Pérez, en Venezuela (1993); Joaquín Balaguer, en República Dominicana (1994), Raúl Cubas Grau, en Paraguay (1999); Alberto Fujimori, en Perú (2000), y Fernando de la Rúa, en Argentina (2001). Véase, sobre el particular, Valenzuela (2004).
} 
nos años atrás: “América Latina: Democrática e Ingobernable” (Semanario “Siete+7”, Santiago de Chile, 29 de noviembre de 2002). Por un lado, se consolida la democracia electoral, con elecciones libres, competitivas y transparentes, y niveles no despreciables de participación electoral; por otro lado, sin embargo, existe un fuerte “déficit democrático” en la región, referido principalmente a la brecha que se advierte entre aspiraciones y realidades (PNUD, 2004).

Transitar desde el autoritarismo a la democracia ha sido, sin duda alguna, un gran logro para la región. De hecho, podemos hablar derechamente de una consolidación de la democracia en América Latina, si por tal entendemos la institucionalización de elecciones libres y competitivas (O’Donnell, 1996). Sin embargo, estamos aún lejos de llegar a una verdadera democracia representativa, en la medida que muchos de los países de la región dan cuenta de situaciones democráticas —en muchos casos, ni siquiera cabe hablar de "regímenes” democráticos propiamente tales- caracterizadas por la fragilidad de sus instituciones y la debilidad de los estados, cuando no de formas de democracia personalistas y plebiscitarias que muchas veces llegan a constituirse en una seria amenaza para la subsistencia misma de la democracia representativa y sus instituciones.

El tránsito desde la democracia electoral hacia una democracia representativa, o de instituciones, debe acometerse en la perspectiva más amplia de la gobernabilidad democrática. Es en torno a estas tres coordenadas - democracia electoral, democracia representativa, entendida como “democracia de instituciones”, y gobernabilidad democrática-, que discurre la presente reflexión. Tratándose de un proceso, argumentaremos que es sobre la base de la gradualidad y el reformismo que debe recorrerse este camino de profundización democrática en América Latina. Administrar los tiempos de espera y dotar a estos últimos de la necesaria legitimidad, aparece como uno de los principales desafíos a resolver.

Democracia electoral. Tal vez la gran lección que hayamos podido aprender en América Latina, en nuestra historia más reciente, es la del valor intrínseco de la democracia política. Acostumbrados a toda una literatura en el campo de las ciencias sociales acerca de los "requisitos", "pre-requisitos”, o condiciones “estructurales” para la democracia -la que parecía reservada para países de alto desarrollo económico, o de ciertas características culturales-, hemos sido sorprendidos por la persistencia de la democracia en la región, en esta última ola democratizadora iniciada hacia fines de 
la década de $1970^{6}$. El hecho de vivir en una era post-autoritaria, postrevolucionaria, post-marxista, y de la post-guerra fría, con el desmoronamiento de totalitarismos y autoritarismos de distinto signo, salvo algunos vestigios del antiguo régimen, seguramente tiene mucho que ver con esta revalorización de la democracia política y sus instituciones. Los derechos humanos y la democracia se constituyen en aspectos centrales y medulares del proceso de globalización que vivimos en todos los ámbitos de la vida social, económica, política y cultural. La democracia goza así de una nueva legitimidad, aunque subsisten grandes problemas y desafíos desde el punto de vista de su eficacia práctica, la calidad de sus instituciones, y los problemas y desafíos en términos de la gobernabilidad.

Constituye un hecho sólido y alentador que, desde fines de 2005, hayamos completado quince elecciones presidenciales, libres y democráticas, en América Latina (en muchos de estos países también se han renovado las autoridades legislativas y locales). En ocho de estas quince elecciones (Costa Rica, Perú, Colombia, Brasil, Nicaragua, Venezuela, Bolivia y República Dominicana) hubo candidatos que se presentaron a la reelección, con triunfos electorales para siete de ellos (todos menos Bolivia, con la derrota de Jorge Quiroga): tres fueron casos de reelección alterna (Óscar Arias, en Costa Rica, Daniel Ortega, en Nicaragua, y Alan García, en el Perú) y cuatro de reelección inmediata (Álvaro Uribe, en Colombia, Luis Inácio Lula da Silva, en Brasil, Hugo Chávez, en Venezuela, y Leonel Fernández, en República Dominicana). Adicionalmente, en dos de las quince elecciones resultaron electos candidatos de la misma coalición gobernante, correspondiendo a dos mujeres: Michelle Bachelet, en Chile, y Cristina Fernández, en Argentina. El oficialismo ganó en ocho casos, mientras que la oposición ganó en los otros siete casos (Zovatto, 2007).

La democracia electoral suele asociarse a una concepción "procedimental” o "minimalista" de democracia, en la tradición de Joseph Schumpeter y Robert Dahl. De acuerdo a esta concepción, los siguientes son los elementos que deben ser comprendidos en una definición de democracia: la existencia de elecciones abiertas y competitivas, sin fraude, coerción o proscripciones, que determinan, a su vez, quién establece las políticas públicas, permitiendo la posibilidad de la alternancia en el poder; la existencia

${ }^{6}$ Según Smith (2005, p. 32), sólo Argentina, Chile, Colombia y Uruguay habrían formado parte de la "primera ola" de democratización. En la "segunda ola" habría que sumar a Costa Rica, Venezuela, Bolivia, Brasil, Perú y Ecuador, con lo que se llegaría a 10 países, de un total de 19. América Central, con la sola excepción de Costa Rica y México, se habría incorporado como democracias electorales recién bajo la "tercera ola” democratizadora. 
de sufragio universal adulto y, finalmente, la garantía de ciertos derechos civiles tradicionales como la libertad de expresión y de organización, y el debido proceso (Mainwaring y Shugart, 1997, p. 14). Otros añaden la subordinación efectiva de los militares a las autoridades legítimamente constituidas.

Si nos atenemos al Índice de Freedom House (www.freedomhouse.org 2008), que mide los grados de libertad política y respeto por las libertades civiles, tendríamos que, en América Latina, 10 de los 19 países de la región podrían considerarse como países "libres": Argentina, Brasil, Chile, Costa Rica, El Salvador, México, Panamá, Perú, República Dominicana y Uruguay. Por su parte, 8 de los 19 países latinoamericanos podrían considerarse como "parcialmente libres": Bolivia, Colombia, Ecuador, Guatemala, Honduras, Nicaragua, Paraguay y Venezuela, mientras que sólo Cuba correspondería a un país "no libre" en la región.

Por su parte, una adaptación del Índice de Democracia de The Economist (www.economist.com/media/pdf/Democracy_Index_2007_v3.pdf), que considera cinco indicadores ${ }^{7}$, y que va más allá de la democracia electoral, para incluir aspectos cualitativos o sustantivos, nos da el siguiente resultado para América Latina (se indica entre paréntesis el lugar que ocupa cada país entre los 165 países considerados en el mundo):

Democracias “completas” (1-27)

Costa Rica (25)

Uruguay (27)

Chile (30) ${ }^{8}$

${ }^{7}$ La realización de elecciones libres, transparentes y competitivas (democracia electoral); el respeto por las libertades civiles como un aspecto de la "democracia liberal"; el funcionamiento del gobierno, de acuerdo al grado de implementación de las decisiones gubernamentales; la participación electoral, como un aspecto de la participación de los ciudadanos en la vida pública, y la existencia de una cultura política democrática. El informe anual de The Economist Intelligence Unit's Index of Democracy (2007), que incluye un total de 165 estados, no considera los niveles de bienestar económico y social, pues, según señala, una variedad de niveles socio-económicos son compatibles con la democracia política.

${ }^{8}$ Hemos incluido a Chile en esta categoría porque, a pesar de que The Economist lo incluye en la categoría de democracias "imperfectas", los puntajes que lo separan con Costa Rica y Uruguay son insignificantes. Adicionalmente porque, de lo contrario, Chile aparecería junto a países latinoamericanos como Bolivia (81), Guatemala (77), Perú (75) y Paraguay (71) que están mucho más atrás en la lista, pero bajo la misma denominación de democracias "imperfectas" o "defectuosas". 
Democracias “imperfectas” (o “defectuosas”) (29-81)

Brasil (42)

Panamá (44)

México (53)

Argentina (54)

Colombia (67)

Honduras (69)

El Salvador (70)

Paraguay (71)

República Dominicana (74)

Perú (75)

Guatemala (77)

Bolivia (81)

Regímenes “híbridos” (83-112)

Nicaragua (89)

Ecuador (92)

Venezuela (93)

Regímenes autoritarios (113-167)

Cuba (124).

Como región, cabe hacer presente que América Latina aparece en el tercer lugar del Índice de Democracia; es decir, está por debajo de América del Norte y Europa Occidental, pero por encima del Caribe, Europa del Este, Asia y Australia, el África subsahariana y Medio Oriente y África del Norte. La mayoría de las democracias "imperfectas" se encuentran en América Latina, Europa del Este y, en menor medida, en Asia. En el caso de América Latina, el informe señala que, a pesar de los avances de los últimos años, bajo la reciente ola democratizadora, muchos de los países de la región permanecen como democracias "frágiles", especialmente en términos de niveles de participación política (muy bajos, comparativamente) y cultura democrática, con el fenómeno del "caudillismo", y otros elementos que la hacen aparecer, comparativamente, en una posición de debilidad.

Desde el punto de vista de las percepciones ciudadanas, subsiste una evaluación que da cuenta de luces y sombras en relación a la democracia. Por un lado, existe una cierta legitimidad de la democracia que puede considerarse como aceptable. Así, por ejemplo, según Latinobarómetro 
(www.latinobarometro.org, 2007), un poco más de la mitad (54\%) de los latinoamericanos considera que la democracia es preferible a cualquier otra forma de gobierno, mientras que un 74\% está de acuerdo o muy de acuerdo con la afirmación de que la democracia puede tener sus problemas pero es el mejor sistema de gobierno (“democracia churchiliana”). Sin embargo, sólo un 37\% se muestra muy satisfecho o más bien satisfecho con el "funcionamiento” de la democracia, a la vez que sólo un 20\% tiene confianza en los partidos políticos, y un $27 \%$ tiene confianza en el parlamento — cabe hacer notar que un $17 \%$ considera que, en algunas circunstancias, un gobierno autoritario puede ser preferible. Existiría, pues, un grado aceptable de apoyo a la democracia en la región, desde el punto de vista de su legitimidad, pero un grado considerable de insatisfacción, desde el punto de vista de su funcionamiento y eficacia práctica.

A pesar de las insuficiencias, no debe perderse de vista que, en una perspectiva histórica, esta tercera ola democratizadora en la región da cuenta de un importante nivel de estabilidad política. Hay más apoyo popular y de las elites a la democracia que en el pasado — aunque subsiste un déficit normativo, en cuanto al soporte valórico de la democracia- y, contrariamente a lo sucedido en la historia de América Latina, los episodios de inestabilidad política no han ido acompañados de quiebres democráticos y golpes de Estado. Tal vez la demostración más evidente de esto último es que los casos de acusación constitucional (impeachment) —que constituyen una forma extrema de fracaso político, y que proliferaron con singular fuerza entre 1992 y 2004-, han sido mecanismos institucionales para resolver episodios de crisis política, sin recurrir a intervenciones militares. Como señala Aníbal Pérez-Liñán, América Latina experimenta nuevas formas de inestabilidad política, muy distintas de las que se conocieron en el pasado: “como en décadas anteriores, gobiernos que han sido democráticamente electos siguen experimentando procesos de quiebre, pero, contrariamente a lo ocurrido en décadas anteriores, los regímenes democráticos no experimentan quiebres” (Pérez-Liñán, p. 3) ${ }^{9}$.

Democracia representativa. Las fuerzas económicas y sociales no actúan en un vacío político. Surge, así, como aspecto central del desarrollo económico y social, la necesidad de la política y de las instituciones (Payne,

${ }^{9}$ Esta “paradoja de estabilidad de regímenes democráticos” se daría con el trasfondo de una forma presidencial de gobierno, como es propio del impeachment, y de un tipo de relaciones entre ejecutivo y legislativo que demostraría que este último no está tan desprovisto de recursos de poder institucionales como suele creerse en la realidad de una región marcada por un fuerte predominio de los presidentes y los ejecutivos. 
Zovatto y Díaz, 2006). De hecho, el “neo-institucionalismo” ha sido la escuela predominante en el campo de las ciencias sociales en las últimas dos décadas, principalmente en la economía y la ciencia política. Fue bajo la inspiración de Douglas North, y desde la perspectiva de la economía, que primero se planeó la importancia de las instituciones en la perspectiva del desarrollo (North, 1990). El marcado economicismo comúnmente asociado a las reformas económicas de la década de 1990 y, principalmente en torno al llamado “Consenso de Washington” (Williamson, 1990), no hizo sino reforzar la necesidad de contar con un marco institucional que les diera sustentabilidad a los procesos económicos y al desarrollo. Más aún, las reformas de mercado hacían necesario no sólo contar con un adecuado marco institucional, sino con un estado capaz de asegurar condiciones adecuadas de gobernabilidad (Naim, p. 32). Bajo esta lógica surgieron las reformas de "segunda generación” encaminadas, justamente, a fortalecer las capacidades estatales $^{10}$. La trayectoria, pues, del debate intelectual y académico, y de los procesos políticos y de toma de decisiones en el campo de las políticas públicas, ha tenido como ejes temáticos las reformas económicas (de mercado), las instituciones, y los estados, en el contexto más amplio de los procesos de democratización en la región.

A decir verdad, no es la democracia como tal la que está en crisis en América Latina. Ya hemos dicho que ésta goza de una legitimidad como nunca antes en la región, sin perjuicio del malestar y el descontento que también existen respecto de ella, especialmente en torno a su funcionamiento. Son los sistemas políticos mismos, y las distintas combinaciones de presidencialismo, multipartidismo y representación proporcional que se conocen en la región, los que explican muchas de las dificultades por consolidar una democracia estable. Así, por ejemplo, variando de un lugar a otro, el hiper-presidencialismo (presidencialismo reforzado o "presidencialismo imperial”), el gobierno por decreto presidencial, el deterioro y creciente desprestigio de la actividad legislativa, la proliferación de asambleas constituyentes, la fragmentación partidaria, los gobiernos de minoría, los sistemas electorales de representación proporcional sin límite y la consiguiente dificultad para formar coaliciones estables y mayoritarias de gobierno, la falta de correspondencia entre las mayorías representadas en el ejecutivo y el legislativo, la proliferación de elecciones y la no concurrencia o simultanei-

10 El propio John Williamson, quien acuñara el término del "Consenso de Washington”, en su —a estas alturas— clásico trabajo sobre ajuste económico en América Latina, ahora junto a Pedro Pablo Kuczynski (2003), reconoce estos vacíos y la necesidad de avanzar hacia una mirada más comprehensiva que incluya el tema de las políticas sociales, y los factores políticos e institucionales que inciden en el desarrollo. 
dad entre elecciones presidenciales y parlamentarias, la ausencia de mecanismos efectivos de pesos y contrapesos (checks and balances) y de control y rendición de cuentas (accountability), horizontales y verticales, la ausencia de una administración pública profesional (civil service), apoyada en cuadros técnicos competentes, y de mecanismos adecuados que velen por la equidad y la transparencia en términos del financiamiento de la política y las elecciones, todo lo anterior en el contexto de una cultura política y unas estructuras políticas caracterizadas, muchas veces, por la realidad extendida del clientelismo, el patrimonialismo, y la corrupción, son algunos de los elementos que dificultan la consolidación de la democracia en la región, bajo condiciones aceptables de gobernabilidad.

En el centro de esas insuficiencias o debilidades está la fragilidad de las instituciones de la democracia representativa, como los partidos, los parlamentos, y los tribunales de justicia, entre otros. Algunos estudios procuran explicar este malestar recurriendo a la hipótesis de una "crisis de representación”, la que se expresaría en el deteriorado prestigio de las instituciones de la democracia representativa, como los partidos y los parlamentos, entre otros, y que se explicaría ya sea por la debilidad o precariedad de las instituciones, o bien por las deficiencias en el nivel de los estados (o por ambos) (Mainwaring, Bejarano y Pizarro, 2006). Sea como fuere, ni la nueva legitimidad democrática que caracteriza a esta ola de democratización en América Latina, ni la institucionalización de elecciones libres, transparentes y competitivas (consolidación democrática), ni los procesos de reforma económica y el mayor dinamismo económico de los años 2003-2007, han sido capaces, por sí mismos, de establecer condiciones aceptables de gobernabilidad.

Puede decirse que, con haber transitado con bastante éxito desde la dictadura hacia la democracia electoral, aún estamos lejos de haber consolidado una auténtica democracia representativa en América Latina. Esto último pasa necesariamente por asegurar, fortalecer y perfeccionar las instituciones de dicho régimen político; a saber, gobiernos y parlamentos elegidos en forma libre y democrática, actuando con estricto apego a la Constitución y a la Ley; vigencia efectiva del estado de derecho; igualdad ante la ley; gobierno de la mayoría y respeto por las minorías; pluralismo político; un Poder Judicial independiente, con órganos transparentes y eficaces, capaces de velar efectivamente por los derechos de las personas y el equilibrio entre los poderes del estado; partidos políticos sólidos y estables que actúen como vehículos efectivos de representación política; respeto y protección por los derechos y libertades fundamentales, entre otros aspectos fundamentales. La sola enumeración de estas características clásicas de la 
democracia representativa, dejan en evidencia la enorme brecha que separa a la democracia electoral de esta última. En este contexto, la democracia representativa aparece, en la realidad de América Latina, más como una aspiración que como una realidad.

La aspiración que aquí manifestamos en términos de la necesidad de avanzar hacia una auténtica democracia representativa, no es el resultado de un ejercicio puramente teórico, académico o intelectual. Cabe recordar y tener presente que todo el sistema interamericano, desde la Carta de la OEA, de 1948, hasta la más reciente Carta Democrática Interamericana, de 11 de septiembre de 2001, está construido expresa y declaradamente sobre la base de la “democracia representativa”. En efecto, ya en el preámbulo de la Carta, la democracia representativa fue considerada como "una condición indispensable para la estabilidad, la paz y el desarrollo de la región”, mientras que su promoción y consolidación fueron considerados como uno de los “propósitos esenciales” y “principios” de la misma, apuntando a un "ejercicio efectivo" de la democracia representativa. Por su parte, la Resolución 1080, de 1991, “Sobre la Democracia Representativa”, creó una serie de mecanismos para hacerla operativa, de una manera efectiva, a la vez que la Carta Democrática Interamericana, de 11 de Septiembre de 2001, llegó a definir los "elementos esenciales" de la democracia representativa en términos del respeto por los derechos humanos y las libertades fundamentales, el apego al estado de derecho, la realización de elecciones periódicas, libres y transparentes basadas en el voto secreto y el sufragio universal como expresión de la soberanía popular, un sistema pluralista de partidos y organizaciones políticas, y la separación e independencia de los poderes del estado. Por su parte, la Primera Cumbre de las Américas, celebrada en Miami en 1994, declaró que la democracia representativa es el "único sistema político" capaz de garantizar ciertos derechos y libertades fundamentales. De esta manera, la adhesión al sistema de democracia representativa constituye un compromiso ineludible de los 34 estados americanos y, más aún, la columna vertebral de todo el sistema interamericano.

Para que la gobernabilidad democrática haga posible la cohesión social $^{11}$, se requiere de un sistema político que goce de legitimidad y eficacia práctica. Sólo puede reunir estas características un sistema que sea verdaderamente representativo; un sistema que sea expresión, a su vez, de la diversidad social, capaz de diseñar e implementar políticas públicas que logren equilibrar el crecimiento de la economía, una efectiva igualdad de oportunidades y la protección de los más débiles. Afirmamos, en este senti-

${ }^{11}$ Sobre este último concepto, véase Tironi, 2008a, Tironi, 2008b, Valenzuela et al., 2008, y Gasparini et al., 2008. 
do, que no hay sustituto para la democracia representativa. A decir verdad, no existe más que la democracia representativa. Todas las democracias conocidas, que pueden considerarse exitosas, corresponden a esta forma política de gobierno. Los mecanismos de participación y formas de "empoderamiento" (empowerment) ciudadano deben canalizarse a través de las instituciones de la democracia representativa. El traslado de la política a la calle es una seria amenaza para el buen funcionamiento de las instituciones. La política entendida en torno a modalidades de "acción directa" de las masas, en un sentido meramente contestatario, ya sea bajo ideologías anarquistas, fascistas, o populistas, son incompatibles con la concepción de democracia representativa que aquí desarrollamos (Flisfisch, 2008). En algún sentido importante, una genuina noción de ciudadanía bajo una concepción democrática y republicana de gobierno es aquella que se basa en la primacía de las instituciones.

En esta perspectiva, compartimos con Brennan y Hamlin (1999) que la democracia representativa es un first-best y una "alternativa política superior”, especialmente cuando se le compara con la llamada democracia “directa”, y sus diversas variantes y modalidades. Como los mismos autores lo señalan, ha existido una cierta tendencia en el campo de la teoría democrática que atribuye a la democracia directa las características de una forma superior de democracia, pero impracticable o, al menos, difícil de llevar a la práctica. Frente a esa realidad, se aceptaría la modalidad indirecta de mediación y toma de decisiones, que sería la democracia representativa, entendida como un "second-best". La realidad de las democracias realmente existentes, sin embargo, y las que pueden considerarse como exitosas en el mundo, demuestran lo contrario; a saber, que la democracia representativa aparece como una forma superior de gobierno, cuando se le compara con la democracia directa. Adicionalmente, la democracia representativa es el régimen político menos oneroso de imponer. Otros son posibles, pero sobre la base de una dosis extraordinaria de coerción. Piénsese, por ejemplo, en la experiencia de las llamadas “democracias populares” (comunismo), o las “democracias orgánicas” (fascismo, nazismo), a lo largo del siglo XX, o las más recientes experiencias de los regímenes burocrático-autoritarios en el Cono Sur de América Latina — principalmente el caso chileno-, en torno al concepto de “democracia protegida” (del pueblo, principalmente), como algunas de las alternativas que se han propuesto a la democracia representativa, de origen liberal. A continuación nos referiremos a la propuesta más actual, en América del Sur, de un tipo de democracia "directa” o “participativa”. 
Democracia “directa” o “participativa”. La crisis de representación y el "déficit democrático” que se advierten en América Latina, no se resuelven sobre la base de sustituir, sino de perfeccionar y profundizar la democracia representativa y sus instituciones. En la historia de esta reciente ola democratizadora en América Latina hemos conocido de muchos intentos por sustituir el normal funcionamiento de las instituciones de la democracia representativa, por formas de democracia “directa” o "participativa”. Así, por ejemplo, entre 1978 y 2005 tuvieron lugar en la región 35 consultas populares en once países (cinco de ellas bajo situaciones autoritarias) (Zovatto, 2006). Hay que reconocer que, muchas veces, esta apelación se hace justamente a partir del bajo prestigio y legitimidad de instituciones como los partidos y los parlamentos, la política y los políticos. Estas formas de democracia directa tienden, supuestamente, a reforzar los mecanismos de participación directa de los ciudadanos. Sin embargo, en la práctica, muchas veces se cae en una verdadera manipulación de la opinión pública y del electorado, sin las “distorsiones” de los mecanismos de intermediación política que son propios de la democracia representativa, como los partidos y los parlamentos, y las instituciones comúnmente asociadas a un estado de derecho, como un poder judicial independiente, una corte suprema que vele efectivamente por la vigencia de los derechos y libertades fundamentales, o un tribunal constitucional que asegure la vigencia y supremacía de la Constitución y las garantías democráticas que le son inherentes. La apelación directa a las masas (opinión pública), el gobierno por decreto presidencial, al margen de las instituciones y procedimientos de la democracia deliberativa y representativa, el uso y abuso de las convocatorias a asambleas constituyentes, entre otros, son algunas de las prácticas recurrentes detrás de este tipo de apelación.

Muchas veces, detrás de la apelación a una cierta forma de democracia “directa” o "participativa”, se esconde la realidad y la práctica de una democracia personalista, populista, plebiscitaria y "delegativa”"12. Esta forma de democracia directa o participativa se presenta, las más de las veces, como una alternativa y una forma superior de democracia, lo que suele traducirse, en la práctica concreta de su funcionamiento, en un cuestionamiento de las instituciones de la democracia representativa. Es cierto que, a diferencia del viejo populismo, surgido bajo la oleada autoritaria de las dé-

12 En la historia más reciente de América Latina, O’Donnell (op. cit., 1996) dice que estaríamos en presencia de democracias “delegativas”, caracterizadas por la existencia de "un ejecutivo cesarista y plebiscitario que, una vez electo, se siente empoderado (empowered) para gobernar como le plazca”. Véase también O’Donnell (1994). Sobre esta oposición entre democracia representativa, por un lado, y democracia personalista, populista, plebiscitaria y delegativa, por otro, véase Diamond (1999). 
cadas de 1930 y 1940, este nuevo populismo surge, no sólo bajo una oleada democrática, sino con las características de una legitimidad democrática formal, como lo demuestra el hecho que sus figuras más emblemáticas han sido elegidas en las urnas. Sin embargo, en última instancia, son las características personales del líder carismático, y su identificación con las masas, y no el papel central de las instituciones, los elementos que definen las características de este tipo de regímenes. Como ha dicho un autor, "a diferencia del populismo histórico, el neo-populismo está involucrado en el juego democrático. Acepta las reglas de la competencia política, pero al mismo tiempo apela a las cualidades superiores y la legitimidad del líder, que se presenta a sí mismo como el redentor y la encarnación del pueblo y de la nación” (René Mayorga, en Mainwaring, Bejarano, y Leongómez, 2006, p. 135).

Bajo el temor y la crítica a la globalización y el neo-liberalismo, y la sensación de desamparo asociada a ambos, se tiende a buscar refugio o protección en el viejo modelo del líder carismático y el estado nacional y popular. La emergencia de la democracia y la economía de mercado tienen un sentido bivalente para la gente: entusiasmo por las oportunidades y temor al desamparo. Si lo que predomina es el temor al desamparo por sobre el entusiasmo por las oportunidades, la gente corre detrás de los caudillos, de sus propuestas de democracia “con apellido”, y entonces los sistemas democráticos se ven afectados, amenazados, o erosionados en sus bases fundamentales. No podemos desconocer que este tipo de regímenes "con apellido” tienen bases sociales reales. La historia de "caciquismo”, “caudillismo” y ejercicio personalista del poder, tiene importantes antecedentes en la historia pre-colombina (caciquismo), colonial, y post-colonial (caudillismo) en América Latina, en el contexto de una cultura política y unas estructuras patrimonialistas, o neo-patrimonialistas, que impiden trazar una clara línea divisoria entre la esfera de lo público y de lo privado. Es más, en general, este tipo de régimen personalista es el producto o desenlace de una compleja trama de acontecimientos y situaciones que tienden a sumir a los pueblos en el malestar y la desesperanza.

En la base de este nuevo populismo encontramos la crisis de los sistemas políticos tradicionales, de sus sistemas de partidos y sus liderazgos; el surgimiento de nuevas demandas y movimientos sociales que no logran ser satisfechas o canalizadas por estos sistemas tradicionales; y la experiencia reciente, en la década de 1980 y de 1990, de experimentos neoliberales en extremo simplistas y dogmáticos, con graves consecuencias sociales y políticas. En este sentido, afirmamos que el problema de América Latina no es el populismo, en sí mismo, sino las causas que lo originan. Muchas veces el fenómeno populista logra apelar a sentimientos y emocio- 
nes que no encuentran eco, ni acogida, en los procedimientos formales de la democracia representativa, cuyas instituciones son vistas, a veces, como ajenas a la vida cotidiana de las personas, especialmente de los sectores populares. En muchos sentidos, este nuevo populismo ha venido a llenar, en el plano simbólico, el vacío dejado por las instituciones políticas de la democracia representativa, las que son vistas como lejanas y meramente formales, cuando no corruptas o en proceso de descomposición.

Nada de lo dicho anteriormente debe conducir a descartar la existencia de un espacio importante, en condiciones adecuadas, para la consulta directa y la participación ciudadana. Este es, típicamente, el caso del gobierno local, en que la participación directa de los vecinos y ciudadanos es, no sólo posible, sino a veces deseable o recomendable, en cuestiones que atañen a los municipios, intendencias y prefecturas, entre otras formas administrativas del gobierno local. La modalidad de elaboración de presupuestos participativos, o la determinación de prioridades en la ejecución de los presupuestos, son algunos de los ejemplos que podríamos citar, y que se han intentado, con resultados mejores y peores, variando de un lugar a otro. También es posible concebir plebiscitos o referendos que tengan lugar frente a coyunturas críticas como cambios de régimen político, o temas de interés nacional en que se haga necesaria o conveniente la consulta directa a la ciudadanía. Se trata, en todo caso, de que estos mecanismos de democracia directa complementen, pero en ningún caso sustituyan, el normal funcionamiento de la democracia representativa y sus instituciones. Los plebiscitos, los referendos y los mecanismos de participación ciudadana propios de la democracia directa deben ser la excepción y no la regla.

Democracia de Instituciones. Institucionalización vs. personalización del poder: he ahí uno de los principales dilemas a resolver en América Latina, en lo que concierne a la cuestión de la democracia como régimen político de gobierno. Existe en la región, tal como hemos argumentado, una evidente tensión entre la democracia política —o democracia representativa, o democracia de instituciones, que aquí utilizamos indistintamente- y la democracia personalista, populista, plebiscitaria y delegativa, que, bajo la apelación a una democracia supuestamente “directa” o “participativa”, termina por amenazar, desconocer, o suprimir, el valor y la vigencia de las instituciones de la democracia representativa. Bajo la invocación a una democracia "de resultados", basada en la idea de una "igualdad real”, y la vieja contraposición entre democracia “sustantiva” y “formal”, se esconde el peligro de socavar las bases mismas, para terminar cancelando, la igualdad formal que es propia de la democracia representativa y sus institucio- 
nes. Es la vieja cuestión de la democracia formal vs. la democracia sustantiva.

Siguiendo a Przeworski (1991, p. 39), definimos la democracia como un "sistema de instituciones", que aspira a obtener la adhesión espontánea de las principales fuerzas políticas (principalmente los partidos), basada en la competencia político-electoral y la incertidumbre sobre los resultados”"13. Es esto lo característico de la democracia como régimen político de gobierno. Son las instituciones las que hacen la diferencia. Afirmamos que es la democracia de instituciones, entendida esta última como un sistema político auto-sustentable capaz de producir resultados concretos para sus ciudadanos, la más conducente y la más funcional al objetivo de la gobernabilidad democrática. Lo anterior es particularmente pertinente en términos de la consolidación democrática en un contexto favorable para la aparición de liderazgos personalistas en la región. Así, el mayor y mejor antídoto contra la democracia personalista está en la consolidación de instituciones políticas democráticas; esto es, en reglas del juego o de procedimiento capaces de aplanar la cancha para que todos los jugadores puedan participar en condiciones de igualdad. La democracia debe entenderse como un sistema de instituciones capaz de garantizar que la discrecionalidad en el ejercicio de los derechos y atribuciones de los gobernantes estará acotada. Hay una tensión evidente, y una suerte de "trade-off”, entre la fortaleza de las instituciones y la aparición de liderazgos personalistas, tan propios de la tradición caciquista y caudillista de América Latina: a mayor fortaleza institucional, más acotados los liderazgos personales. El problema existe especialmente cuando los liderazgos personales concentran grandes cuotas de poder en contextos de debilidad institucional. En cambio, cuando las instituciones son sólidas y fuertes, los liderazgos personalistas pueden desarrollarse en contextos acotados. El argumento anterior no va dirigido contra el papel necesario e insustituible de los liderazgos en las democracias, sino contra la idea de que los liderazgos pueden llegar a sustituir a las

13 La democracia, según el autor, correspondería a un sistema en que "los partidos pierden elecciones"; correspondería, en este sentido, a la "institucionalización de la incertidumbre". Para ser perdurable, la democracia debe concitar la adhesión espontánea de las principales fuerzas políticas, basada en la persecución de su propio interés particular (self-interest). Siguiendo la teoría de juegos, el autor argumenta que la democracia debe entenderse en términos de un equilibrio de estrategias descentralizadas de fuerzas políticas autónomas. La democracia provee del "marco institucional" que hace posible la competencia de múltiples fuerzas políticas —en ese sentido sería un "sistema de instituciones". Son las instituciones y el libre juego de las fuerzas políticas que persiguen su propio interés particular, las que hacen posible un equilibrio y un "sistema de auto-gobierno". 
instituciones. Se hace necesaria una adecuada relación entre instituciones y liderazgos para el fortalecimiento de la democracia ${ }^{14}$.

De esta manera, el énfasis en la democracia de instituciones no debe llevar a subestimar el papel insustituible de los liderazgos y los actores políticos. Las instituciones actúan como sistemas de incentivos sobre actores políticos que se mueven intencionalmente. Las instituciones políticas corresponden a arreglos institucionales que afectan -incentivando o restringiendo - el comportamiento de los actores políticos. Las instituciones pueden ser indudablemente cambiadas y perfeccionadas, pero hay límites a la ingeniería institucional. Las representaciones, preferencias y orientaciones de los actores deben ser tenidos especialmente en cuenta. Si bien las instituciones y los arreglos institucionales pueden llegar a hacer la diferencia desde el punto de vista de la estabilidad y la gobernabilidad democrática, ello no puede ser visto al margen del tipo de liderazgos y el papel que los actores políticos juegan en el proceso democrático.

Lo cierto es que, con ser un gran avance, no basta con la democracia electoral para consolidar una democracia estable en América Latina, en condiciones aceptables de gobernabilidad. En un informe reciente, el PNUD (2004) llama a avanzar desde la "democracia electoral” — la que considera como un avance significativo en la historia reciente de América Latinahacia una "democracia de ciudadanos y ciudadanas". Esta última es vista como una forma superior a una concepción meramente minimalista o procedimental de la democracia. Sostiene que la democracia es más que un simple método para elegir a los gobernantes. Es la vieja y siempre actual cuestión de la persona entendida como sujeto de derechos y deberes, en la perspectiva más amplia de una "plena ciudadanía” entendida como el ejercicio efectivo de los derechos políticos, civiles y sociales. La democracia es vista como una "parte integral” de esta concepción más amplia de derechos, en que es el ciudadano o ciudadana, más que el simple elector, el actor fundamental. Sin desconocer los resultados obtenidos en términos del ejercicio de los derechos políticos, al interior de la democracia electoral, esta propuesta apunta a ampliar de manera efectiva la “ciudadanía social”. La democracia debe ser vista en términos de su capacidad para hacer efectivos los derechos de los ciudadanos, incluida la amplia gama de derechos políticos, civiles y sociales. De esta manera, la democracia electoral no podría considerarse al margen de la persistencia de la pobreza y la desigualdad, los que constituyen el problema más acuciante de América Latina. Así, el “déficit democrático” abarcaría tanto las insuficiencias en el plano de las institucio(2006).

${ }^{14}$ Este argumento se desarrolló con mayor profundidad en Navia y Walker 
nes, lo que requiere de más y mejor democracia, como los desafíos de una mayor igualdad, en la perspectiva de un desarrollo económico y social. Existiría una contradicción entre, por un lado, la igualdad formal de la democracia política, y la desigualdad de facto que encontramos en la región en el ámbito económico-social. En este contexto, la “crisis de la política” no debe entenderse como referida sólo a los partidos y las instituciones representativas, sino también a la ineficacia de los estados para hacerse cargo de las exigencias en el ámbito de la ciudadanía. En síntesis, "la democracia de ciudadanos y ciudadanas es más comprehensiva que el sistema político y la mera existencia de derechos políticos. La democracia debe ser profundizada hasta abarcar el ámbito de los derechos civiles y sociales”. La realidad de estados débiles y democracias frágiles en América Latina, en que subsisten, contradictoriamente, la igualdad legal y la desigualdad de facto harían necesario un esfuerzo en la dirección señalada.

Consideramos que estos contenidos del informe reciente del PNUD, que brevemente hemos reseñado, son perfectamente compatibles con el concepto de “democracia de instituciones” que aquí postulamos. A decir verdad, se trata de un concepto de ciudadanía que no puede ser visto al margen de la cuestión central de las instituciones (como que la ciudadanía es en sí misma una institución, conforme a la tradición de la democracia republicana). Como dijera un senador chileno, "la ciudadanía, para mí, consiste en tomarse en serio las instituciones” (Fernando Flores, diario La Tercera, 30 de junio de 2006). La Democracia de Ciudadanos y Ciudadanas que recoge el informe del PNUD, teniendo como trasfondo las concepciones sobre "desarrollo humano" desarrolladas por Amartya Sen, debe ser vista como un aspecto de la Democracia de Instituciones que postulamos como necesaria y deseable para América Latina, en una perspectiva de profundización de la democracia representativa y sus instituciones.

Tal vez un matiz de diferencia - uno no menor, por cierto- que podríamos anotar entre el informe señalado y lo que hemos expuesto hasta aquí, es que, lo que los autores del informe del PNUD denominan como “pre-condiciones” (o pre-requisitos) — principalmente, en el ámbito económico y social—, para el buen funcionamiento de la democracia, en términos de su capacidad para resolver los problemas de la gente, no deberían ser considerados, a nuestro juicio, como elementos intrínsecos de la democracia política, o democracia representativa, o democracia de instituciones, sino de ciertas exigencias que se le formulan a la democracia en términos de las condiciones de eficacia de la misma, o de su gobernabilidad. Como argumentaremos más adelante, pensamos que esas exigencias, o condiciones de eficacia, se refieren a los desafíos de la “gobernabilidad”, más que a atribu- 
tos inherentes a la democracia como régimen político de gobierno. De hecho, las democracias que conocemos en el mundo, que son, fundamentalmente, y como lo hemos dicho una y otra vez, democracias representativas, conviven, variando de un lugar a otro, con diversos tipos de desigualdad económica y social. Cada sociedad, cada sistema político, debe sí discutir, y pactar, qué grados de desigualdad social está dispuesta a tolerar, a fin de asegurar condiciones adecuadas de gobernabilidad.

Finalmente, postular una democracia representativa como democracia de instituciones no significa una preferencia por tales o cuales instituciones. Tal como se ha tendido a rechazar la pretensión de "recetas únicas" (one-size-fits-all) en el campo de las reformas económicas, así también debe rechazarse tal pretensión en el campo de las reformas institucionales. De hecho, lo que se advierte en América Latina, en nuestra historia más reciente, es una gran (y rica) variedad institucional en la que conviven sistemas federales y unitarios, sistemas electorales proporcionales, mayoritarios y mixtos, y una gran variedad de sistemas de partidos, con diversos grados de institucionalización y fragmentación ${ }^{15}$. Lo mismo ocurre con la forma de gobierno, en que la aparente dificultad de conciliar formas presidenciales con sistemas multipartidistas — lo que ha sido suficientemente documentado en la literatura - va encontrando diversos tipos de respuestas propias de la realidad latinoamericana, como el llamado "presidencialismo de coalición”. Más que mirar el presidencialismo latinoamericano como una suerte de “anomalía”, debe ser visto como un modelo específico que lo ubica en algún lugar intermedio entre el presidencialismo estadounidense — bipartidista, basado en una muy particular fórmula de peso y contrapesos (checks and balances), y una cierta manera de relacionarse entre el ejecutivo y el legislativo- y el parlamentarismo europeo, que correspondería a la forma más acorde de una democracia multipartidista. Lo cierto es que no hay instituciones ideales. Lo anterior también se extiende a la cuestión de la forma de gobierno (presidencialismo o parlamentarismo). Antes bien, existe una variedad institucional que, en la realidad actual de América Latina, debe llevarnos a alejarnos de posturas dogmáticas para asumir una mirada de mayor pragmatismo, escogiendo entre un menú de opciones que pueden ser conducentes al mismo objetivo de asegurar condiciones adecuadas de go-

15 Dani Rodrik señala, en el campo económico, que lo que verdaderamente importa en el nivel de las instituciones es la función que cumplen más que la forma particular que asumen, lo que traduce en la fórmula de one economics, many recipes, o la idea de que "la función de la institución no determina la forma institucional" (Rodrik, 2007). Lo mismo puede decirse de las instituciones políticas, las que pueden adquirir diversas formas, sirviendo a un mismo objetivo o función. 
bernabilidad ${ }^{16}$. Lo que importa, a decir verdad, más allá de tal o cual institución en particular, es la combinación de instituciones, o el tipo de arreglos institucionales que permiten avanzar hacia el objetivo de la gobernabilidad, atendiendo a la realidad de cada país.

Gobernabilidad (governance) democrática. La democracia representativa, o de instituciones, sin embargo, con ser una condición necesaria, no es una condición suficiente para asegurar la gobernabilidad democrática. Antes de pasar al análisis más pormenorizado de esta última, especialmente en lo que se refiere a las instituciones de gobierno en América Latina (Poder Legislativo, Poder Ejecutivo y Poder Judicial), conviene hacer una precisión en relación al concepto mismo de gobernabilidad democrática. Este último término adquiere una cierta complejidad si tomamos lo que, en inglés, se denomina governance, referido a la capacidad de los gobiernos democráticos de producir, o asegurar, ciertos resultados en el campo económico y social. Se le vincula, así, más a las políticas (policies) que a la política, los procesos políticos y las instituciones políticas. Se habla, por ejemplo, del desempeño (delivery) de las democracias, y de su capacidad de asegurar, no sólo ciertas condiciones de legitimidad de las instituciones políticas, sino ciertos resultados en el ámbito económico y social, desde el punto de vista de su eficacia práctica y su funcionamiento. En el trasfondo de esta concepción, se recoge una cierta percepción a nivel de la opinión pública latinoamericana, manifestada en diversos estudios cualitativos y cuantitativos, de que los sistemas políticos - y los estados — darían cuenta de una cierta incapacidad para atender adecuadamente las demandas sociales de la población. Esto conllevaría un riesgo de pérdida de legitimidad del sistema, y eventualmente de ingobernabilidad, con la consiguiente búsqueda de "alternativas" a las instituciones de la democracia representativa.

En el campo de la teoría política y de la política comparada, diversos autores señalan la necesidad de ir más allá de la democracia como régimen político de gobierno, para incluir esta dimensión económica y social. Así,

${ }^{16}$ El mismo Rodrik señala que, en el campo de las reformas de políticas en los países en desarrollo, muchas veces debe optarse por second-best institutions —no necesariamente best-practice institutions - a partir de fallas de mercado o de gobierno en contextos específicos que no pueden ser removidos en el corto plazo. En las experiencias de los países en desarrollo —y también de los países desarrollados- existiría una variedad de formas institucionales para servir a ciertos fines u objetivos. A diferencia del sesgo en favor de las "mejores prácticas" que son postuladas por organismos multilaterales como el BM, el FMI o la OMC, muchas veces los reformadores del mundo real (en desarrollo) operan en un second-best environment (Rodrik, 2008). Lo anterior no significa renunciar a la búsqueda de esas mejores prácticas, sino reconocer que la realidad es mucho más compleja. 
por ejemplo, Adam Przeworski señala la necesidad de vincular el tema de las “instituciones” con el de ciertas “condiciones”, económicas y sociales, en un sentido de resultados sustantivos —es la vieja cuestión, como él mismo señala, de las “condiciones sociales de la democracia” (Przeworski, p. 26). De una manera similar, Guillermo O’Donnell señala que el "régimen democrático" es un "componente fundamental” de la democracia, pero es "insuficiente” para una adecuada conceptualización de la democracia (O’Donnell, 2004, p. 9). Según O’Donnell, la democracia política, o la poliarquía, o el régimen democrático — los que considera términos intercambiables o sinónimos entre sí-, no son suficientes para la cabal comprensión de la democracia en términos de una ciudadanía amplia, como ejercicio de los derechos civiles, políticos y sociales.

Por su parte, Scott Mainwaring y Timothy Scully nos ofrecen una definición de democratic governance en términos de "la capacidad sostenida de los gobiernos democráticos de implementar políticas efectivas con miras al bienestar político, social y económico de un país” (2008, p. 113). Así, una “governanza” democrática exitosa estaría dada por la capacidad de los gobiernos para mantener una razonablemente alta calidad de las prácticas políticas, en términos de contribuir a que sus países progresen económicamente, proveyendo a sus ciudadanos de seguridad, a la vez que haciendo frente, de manera efectiva, a los principales problemas sociales de pobreza, distribución del ingreso y servicios sociales. Se trataría, pues, no sólo de gobernar democráticamente, sino de hacerlo de manera efectiva, velando no sólo por la buena salud de las instituciones democráticas sino por el buen desempeño del estado, en términos de los resultados concretos en el campo de las políticas públicas. Finalmente, entre otros ejemplos que podríamos citar, Payne, Zovatto y Mateo Díaz definen la "gobernabilidad democrática” como una que "incluye la capacidad para adoptar e implementar decisiones que respondan adecuadamente a los problemas económicos y sociales más acuciantes de un país” — con el trasfondo, agregan, de la “inestabilidad política” y la “debilidad institucional” de América Latina entre las décadas de 1950 y 1980 (2006, p. 86).

En estas líneas distinguimos entre lo que son los atributos o cualidades intrínsecas de la democracia como régimen político de gobierno, y lo que son las condiciones, incluidas las de tipo económico y social, desde el punto de vista de las exigencias de la gobernabilidad (governance). En este sentido, afirmamos que la gobernabilidad democrática comprende la estabilidad política, el progreso económico y la paz social (Boeninger, 2007). En un sentido amplio, entendemos por gobernabilidad democrática la capacidad de una sociedad para gobernarse a sí misma y, en un sentido más acotado, 
la capacidad de los sistemas políticos y sus instituciones - y del estado, en definitiva - para absorber, canalizar y procesar, pacíficamente y en términos efectivos, las demandas de la ciudadanía en el ámbito económico y social. Esto se hace particularmente necesario de definir, en términos conceptuales, en el caso de América Latina, enfrentados a una verdadera revolución de las expectativas, como la que tiene lugar en la actualidad, en el marco de los procesos de democratización de las instituciones, crecimiento económico y profundos cambios sociales de la última década y media. Esta revolución de las expectativas implica impaciencias mayores o, dicho de otro modo, un grado menor de tolerancia hacia las desigualdades sociales que permanecen, a través de la historia, como un verdadero elemento de continuidad entre el antes y el después de los recientes - y no tan recientes- procesos de democratización. En última instancia, se trata de la capacidad de la democracia de hacerse cargo del desafío de la cohesión social en América Latina, entendida esta última como "aquella fuerza o acción mediante la cual los individuos pertenecientes a una sociedad se mantienen unidos", o el "pegamento" que aglutina a los miembros de una sociedad entre sí y con la propia sociedad (Tironi, 2008b, pp. 323 y 324).

Los países de América Latina —y de la región en su conjunto, dentro de su "heterogeneidad estructural", y de la enorme diversidad que la caracteriza - han pasado a ser países de ingresos medios, en proceso de integración a la economía mundial, con profundos cambios en sus estructuras económicas y sociales. Con algunas excepciones, ya no se habla de subdesarrollo sino de países - y de una región - en desarrollo. En este sentido, los desafíos de la gobernabilidad democrática imponen a los regímenes democráticos ciertas exigencias que son necesarias de cumplir si se quiere consolidar la estabilidad política, el progreso económico y la paz social. La mejor demostración de que estas exigencias que impone la gobernabilidad sobre los regímenes democráticos, no son atributos inherentes a estos últimos, es que diversas democracias conviven en el mundo con distintos niveles de desarrollo económico y social. Esto, que es cierto, en general, lo es aún más en el caso de América Latina: “América Latina es la única zona que combina regímenes electos democráticamente en todos sus países (salvo Cuba), con altos niveles de pobreza (40\%) y con la distribución más desigual del mundo” (Zovatto, 2007, p. 24). A pesar de los significativos avances en términos de reducción de la pobreza, desde un $48 \%$, en 1990, hasta un 36\%, en 2007, según cifras de la CEPAL, y del crecimiento económico entre un 4 y un 5\% para el período comprendido entre 2003 y 2007, la región sigue siendo, junto con el África subsahariana, la más desigual del mundo. 
En definitiva, sostenemos que la necesidad de un cierto desempeño (“performance”, “delivery”, en términos de “policies” y “governance”) en el ámbito económico y social, debe entenderse como una exigencia que se le formula a la democracia desde el punto de vista de la gobernabilidad, sin que corresponda necesariamente a un elemento intrínseco de la democracia definida como régimen político de gobierno. En otras palabras, la democracia política —o representativa, o de instituciones— puede convivir con distintos niveles de desigualdad social, sin perjuicio de que su desempeño económico y social tendrá efectos desde el punto de vista de la gobernabilidad.

Gradualidad del cambio y legitimidad de la espera. La democracia no debe entenderse sólo en términos de un régimen político de gobierno, referido al papel de las instituciones, sino también como un proceso político. El arte de la política (Cardoso y Setti, 2006), y el arte de gobernar consisten, precisamente, en equilibrar la democracia como "sistema de instituciones", y la democracia como proceso político. Ello nos remite principalmente al tema de los cambios en democracia, y de los ritmos, tiempos, profundidad y modalidades del cambio social. La democracia no excluye el cambio - muy por el contrario, lo hace posible, especialmente en la medida que cuente con instituciones autónomas, adaptables, complejas y coherentes, según la clásica definición de Huntington (1968). La democracia tampoco excluye, ni desconoce, el conflicto que es inherente a toda sociedad - muy por el contrario, la democracia es, hasta cierto punto, la institucionalización del conflicto. Lo que la democracia requiere, a fin de evitar un conflicto generalizado que, a la vez, y dependiendo de las condiciones y circunstancias, pueda devenir en crisis, vacío de poder y, en el extremo, en un proceso de quiebre, es que las instituciones caminen de la mano — por así decirlo_- y en forma coherente, con los procesos políticos y sociales. No cualquier cambio, ni a cualquier ritmo, velocidad, o profundidad, o bajo cualquier modalidad, es tolerado por una democracia representativa o de instituciones, en condiciones adecuadas de gobernabilidad.

Esto es relevante a la luz de nuestra historia más reciente en América Latina. En lo político, la democracia se extiende por la región como nunca antes en nuestra historia. En lo económico, los mercados y el crecimiento juegan un papel fundamental en la perspectiva del desarrollo - aunque están por verse las implicancias y consecuencias de la crisis financiera de septiembre de 2008-, a la vez que, en general, y con distintos grados de avance, la apertura económica y la liberalización del comercio se abren paso acorde con las exigencias de la globalización, en la perspectiva de la inser- 
ción internacional de nuestros países ${ }^{17}$. Con todo, la persistencia de la pobreza y la desigualdad siguen siendo uno de los signos más distintivos y característicos de América Latina. Es aquí, precisamente, donde residen los principales debates y diferencias en la región; particularmente, en torno a la cuestión de cuáles son las políticas sociales y las estrategias de desarrollo más eficaces para hacer frente a la pobreza y la desigualdad. Cómo conciliar democracia política, crecimiento económico y equidad social, es el principal desafío que enfrentan los países de la región.

La persistencia de la pobreza y la desigualdad se hace aún más patente e inaceptable en la medida que hay más democracia y más crecimiento en la región. La democratización, la urbanización y la globalización hacen más visible la exclusión, mientras que se desarrolla una mayor conciencia en lo que se refiere a los costos económicos y políticos de esta última. Todo lo anterior hace necesario asignarle una importancia estratégica a la problemática social, con horizontes de mediano y largo plazo, dándoles continuidad a las políticas, más allá de los ciclos electorales y económicos de corto plazo.

Lo anterior implica una opción estratégica por la estabilidad. El sentido estratégico de las políticas sociales y la continuidad de las mismas suponen un horizonte de estabilidad. Esto último, tanto en términos de estabilidad macropolítica (democracia) como de estabilidad macroeconómica (democracia sin inflación). Así como el estado tiene la obligación de garantizar ciertos bienes públicos tales como la seguridad, tiene también la obligación de asegurar estabilidad macro económica, entendida esta última como un bien público. La inestabilidad golpea principalmente a los sectores de menores ingresos. La estabilidad, en un sentido positivo, es una condición necesaria, aunque no suficiente, del crecimiento económico y la lucha contra la pobreza y la desigualdad. Con el trasfondo de una historia de inestabilidad política, que está dada por las oleadas de democracia y autoritarismo que hemos conocido en la región, y una historia de inestabilidad económica (inflación, híper-inflación, déficit fiscales crónicos, crisis de balanza de pagos, abultadas deudas externas, entre otros), es un imperativo en el nivel de la ética de la responsabilidad asegurar condiciones de estabilidad política y económica para el progreso, el bienestar y el desarrollo de la región. Adicionalmente, los ciclos de la economía, de “boom” y “bust”, y la vulnerabilidad frente a los shocks financieros externos, requieren de una perspectiva de

17 Tenemos muy en cuenta, a este respecto, las conclusiones del documento final de la APEC (Asia Pacific Economic Cooperation), celebrada en Santiago de Chile, en diciembre de 2004, que señalaba que la apertura económica y la liberalización del comercio no deben entenderse como un fin en sí mismo, sino como un medio tras la búsqueda de un "crecimiento equitativo y sustentable". 
futuro, de mediano y largo plazo, que establezca algún tipo de control sobre las variables de corto plazo y los ciclos electorales. La responsabilidad fiscal, las políticas económicas anti-cíclicas, la autonomía de la autoridad monetaria, la existencia de instituciones de mercado - y de instituciones, en general, en términos de reglas del juego claras, estables y equitativas-, y de adecuadas regulaciones económicas, la rendición de cuentas (accountability) y, sobre todo, la construcción de acuerdos básicos, son algunos de los desafíos en la búsqueda de la estabilidad, procurando asegurar un cierto grado de predictibilidad a la vida diaria de los ciudadanos y ciudadanas.

De alguna manera importante, la democracia es una carrera entre la esperanza y la desesperanza; una carrera, por lo tanto, que desconfía de las soluciones — o las promesas de soluciones — inmediatas, de corto plazo, de la noche a la mañana (overnight). Lo anterior requiere de una administración de los tiempos de espera, dotando a estos últimos de la necesaria legitimidad, a fin de asegurar condiciones adecuadas de gobernabilidad. Lo que hay detrás de un cierto (y muy justificado) descontento, malestar o malaise en América Latina, es una suma de injusticias e impaciencias que, muchas veces, se traducen en la búsqueda de un líder carismático que termina por proporcionar una cierta sensación de identidad y pertenencia, bajo la promesa de una satisfacción inmediata de las demandas sociales. De lo que se trata, más bien, es de gobernar de una manera que haga creíble (y legítima) la espera, impidiendo la tentación de cambios radicales, de tipo revolucionario, y de las promesas fáciles, de tipo populista, a la vez que enfrentando las causas, y removiendo las condiciones, que conducen a uno y otro.

Lo anterior requiere de instituciones para la gradualidad, como un aspecto central de lo que hemos denominado "democracia de instituciones”. Se trata de procesos e instituciones que recojan la verdadera naturaleza de la política como el arte de lo posible, en un sentido "hirschmaniano" de "posibilismo" (Hirschman, 1973) ${ }^{18}$. Este argumento no debe entenderse en un sentido conservador, de defensa del status quo, o de un cierto orden social o político. La democracia hace posible el cambio, especialmente en la medida que sepa equilibrar las instituciones políticas y los procesos de cambio. El “posibilismo” busca justamente ir más allá de lo meramente "probable”, que es el ámbito propio de las ciencias sociales, para ampliar los límites de lo posible, sin prejuzgar sobre la profundidad de los cambios, sino más bien velando por la sustentabilidad de los mismos. Se trata, en definiti-

\footnotetext{
${ }^{18}$ Hirschman señala la necesidad de ampliar los límites de lo posible, dentro de la lógica de lo que es posible hacer y obtener. Expresa, a la vez, su desconfianza en el cambio radical, o revolucionario, al que califica de "voluntarismo", y desconfianza también en el rol del "economista puro”, que desconoce la dimensión política de las cosas.
} 
va, del “efecto túnel”, que plantea el propio Hirschman, que es el que permite dotar de legitimidad a la espera; esto es, en la medida que uno es capaz de ver la luz al final del túnel, estará en mejores condiciones de pagar los costos que impone la espera, en el corto plazo.

En términos de las estrategias de desarrollo que se han conocido en la región, del necesario proceso de aprendizaje asociado a las mismas, y de nuestra historia más reciente, esto tiene mucho que ver, siempre en una lógica hirschmaniana, con lo que se ha dado en llamar la "economía política de lo posible”. Esta es lo contrario a la “economía política de lo imposible”, que caracterizó a América Latina en la era de las utopías y las “planificaciones globales”, y a la “economía política de la impaciencia” que caracteriza, muchas veces, a los regímenes populistas ${ }^{19}$. En el fondo, esta concepción de la democracia desconfía profundamente de los “atajos”, y si hay algo que debiéramos haber aprendido en la historia más reciente $-\mathrm{y}$ no tan reciente- de América Latina, es que no hay atajos en el camino del desarrollo y la democracia, para la solución de los grandes problemas socioeconómicos. Es la reforma gradual la que hace posible, viable, y legítimo el cambio social en democracia.

Lo anterior cobra aún mayor importancia y significación en una región, como América Latina, que viene de vuelta —así queremos creerlode los "paradigmas” y utopías que convirtieron a la región en un verdadero laboratorio social en el que distintos “experimentos” tuvieron lugar, generalmente acompañados de una fuerte polarización política. Los costos de estos experimentos de cambio radical, revolucionario o autoritario (o ambos), y la opción por una economía política de lo imposible, o de la impaciencia, generalmente terminaron por pagarlos los pueblos y, muy particularmente, los sectores más pobres y vulnerables de la sociedad. Venimos de vuelta de los paradigmas y nos encaminamos (o debiéramos hacerlo) en la dirección de un mayor pragmatismo, animados por una mirada esperanzada, pero sin ilusiones. En el trasfondo de este tema está también la cuestión de qué tipo de igualdad queremos: si de resultados inmediatos, o de oportunidades efectivas. Los "tiempos de espera” son distintos en uno y otro caso. Los niveles de paciencia o impaciencia también lo son.

Lo anterior remite a la cuestión muy central de qué tipo de desigualdad puede tolerar una democracia. Cambio eficiente es aquél en que algunos mejoran sin que otros empeoren. El problema del neo-liberalismo — que muchas veces aparece como la contraparte del neo-populismo (y a veces se constituye en su antecedente principal) — es que no hay un mayor apoyo o preocupación por la suerte de los “perdedores”. En democracia, especial-

\footnotetext{
${ }^{19}$ Véase, sobre el particular, Santiso (2006).
} 
mente en la era de la globalización, por las percepciones de incertidumbre e inseguridad asociadas a la misma, hay que hacerse cargo de los perdedores y construir redes de protección social que se hagan cargo especialmente de los sectores más vulnerables de la sociedad, que viven entre la incertidumbre y la inseguridad. Lo anterior es particularmente necesario en tiempos de crisis. La espera está muy relacionada con la capacidad de persistir en torno a ciertas convicciones compartidas basadas en la confianza en las instituciones —-más que en los liderazgos personales - y en un sistema de financiamiento estable, y de gestión eficiente, de los programas sociales. Así, pues, el cambio gradual o incremental, y la legitimidad de la espera, se convierten en uno de los principales desafíos que enfrenta América Latina en la hora actual y en una perspectiva de futuro.

\section{REFERENCIAS}

Brennan, Geoffrey y Alan Hamlin (enero 1999): “On Political Representation”. En British Journal of Political Science, Vol. 29, № 1.

Boeninger, Edgardo (2007): Políticas Públicas en Democracia. Institucionalidad y Experiencia Chilena 1990-2006. Santiago: Uqbar editores.

Cardoso, Fernando Henrique y Ricardo Setti (2006): A Arte da Política (a Historia que Vivi). Civilizacao Brasileira.

Diamond, Larry (1999): Developing Democracy (Toward Consolidation). The Johns Hopkins University Press.

Flisfisch, Ángel (septiembre de 2008): “¿Hay Alternativas a la Democracia Representativa? Democracia Representativa, Régimen e Institucionalidad, la Política y los Políticos". Manuscrito. Taller "Círculo de Debates del Futuro", dirigido por Edgardo Boeninger (CIEPLAN).

Gasparini, Leonardo y otros (2008): Polarización Económica, Instituciones y Conflicto (Dinámicas de la Cohesión Latinoamericana). Santiago: Uqbar Editores.

Hagopian, Frances y Scott Mainwaring (2005): The Third Wave of Democratization in Latin America: Advances and Setbacks. Cambridge; New York: Cambridge University Press.

Hirschman, Albert (1973): Desarrollo y América Latina (Obstinación por la Esperanza). FCE.

Huntington, Samuel (1968): Political Order in Changing Societies. Yale University Press.

Mainwaring, Scott, Ana María Bejarano y Eduardo Pizarro Leongómez (2006): The Crisis of Democratic Representation in the Andes. Stanford, Calif.: Stanford University Press.

- y Timothy Scully (July 2008): "Latin America: Eight Lessons for Governance". En Journal of Democracy, Vol. 19, № 3.

- y Matthew Soberg Shugart (1997): Presidentialism and Democracy in Latin America. Cambridge; New York: Cambridge University Press. 
Naim, Moisés (1994): “Latin America: The Second Stage of Reform”. En The Journal of Democracy, 5, No 4 (October).

Navia, Patricio e Ignacio Walker (2006): “Gobernabilidad Democrática en América Latina (Instituciones y Liderazgos)”. En Serie Estudios Socio/Económicos, $\mathrm{N}^{\circ} 29$, CIEPLAN.

North, Douglas (1990): Institutions, Institutional Change and Economic Performance. Cambridge University Press.

O’Donnell, Guillermo (1994): “Delegative Democracy”. En Journal of Democracy, 5, No 1. (1996): "Illusions about Democratic Consolidation". En Larry Diamond y Marc F. Plattner (eds.), The Global Resurgence of Democracies. The Johns Hopkins University Press, 2001.

Payne, Mark J., Daniel Zovatto y Mercedes Mateo Díaz (editores) (2006): La Política Importa (Democracia y Desarrollo en América Latina). BID.

Pérez-Liñán, Aníbal (2007): Presidential Impeachment and the New Political Instability in Latin America. Cambridge Studies in Comparative Perspective.

PNUD (2004): La Democracia en América Latina: Hacia una Democracia de Ciudadanos y Ciudadanas. PNUD.

Przeworski, Adam (1991): Democracy and the Market. Cambridge University Press.

Rodrik, Dani (2007): One Economics, Many Recipes: Globalization, Institutions, and Economic Growth. Princeton: Princeton University Press.

_ (June 2008): “Second-best Institutions”. Working Paper 14050. National Bureau of Economic Research.

Santiso, Javier (2006): La Economía Política de lo Posible en América Latina. BID.

Smith, Peter (2005): Democracy in Latin America (Political Change in Comparative Perspective). Oxford University Press.

Tironi, Eugenio (2008a): “La Cohesión Social Latinoamericana”. Santiago: Uqbar Compactos/CIEPLAN.

- (editor) (2008b): "Redes, Estado y Mercados (Soportes de la Cohesión Social

Latinoamericana)”. Santiago: Uqbar Editores.

Valenzuela, Arturo (2004): "Latin American Presidencies Interrupted”. En Journal of Democracy, 14, No 4.

Valenzuela, Eduardo y otros (2008): "Vínculos, Creencias e Ilusiones (la Cohesión Social de los Latinoamericanos)".

Williamson, John (1990): Latin American Adjustment: How much Has Happened. Institute for International Economics. - y Kuczynski (editores) (2003): After the Washington Consensus. Institute for International Economics.

Zovatto, Daniel, en Latinobarómetro, 2006.

(2007): "Balance Electoral Latinoamericano". En C. Malamud et al., Anuario Iberoamericano. Agencia EFE y Real Instituto Elcano, Ediciones Pirámide. 